\title{
Effects of atmospheric conditions on surface diffuse degassing
}

A. P. Rinaldi ${ }^{1,2}$, J. Vandemeulebrouck ${ }^{3}$, M. Todesco ${ }^{1}$, F. Viveiros ${ }^{4}$

A. P. Rinaldi, Lawrence Berkeley National Laboratory, 1 Cyclotron Road, 94720 Berkeley, California, USA (aprinaldi@lbl.gov, antonio.rinaldi@bo.ingv.it)

M. Todesco, Istituto Nazionale di Geofisica e Vulcanologia, via Donato Creti, 12, 40128 Bologna, Italy. (micol.todesco@bo.ingv.it)

J. Vandemeulebrouck, ISTerre, CNRS, Université de Savoie, Campus Scientifique, 73376 Le Bourget du Lac Cedex, France. (Jean.Vandemeulebrouck@univ-savoie.fr)

F. Viveiros, Centro de Vulcanologia e Avaliação de Riscos Geológicos, Universidade dos Açores, Rua Mãe de Deus, Ponta Delgada, P9501801, Portugal. (Maria.FB.Viveiros@azores.gov.pt)

\footnotetext{
${ }^{1}$ Istituto Nazionale di Geofisica e
} 
3 Abstract. Diffuse degassing and fumarolic activity are secondary man-

4 ifestations of active volcanoes. Monitoring of these manifestations plays a

${ }_{5}$ key role in understanding the activity status of volcanoes, and the installa-

${ }_{6}$ tion of permanent stations to measure the $\mathrm{CO}_{2}$ flux at the surface are be-

7 coming more common. The measured gas fluxes often present a correlation

$\therefore$ with environmental observables, such as air temperature or barometric pres-

9 sure, especially when gas emission is low. An example is the Furnas volcano

${ }_{10}$ (Azores), which features low temperature fumaroles, $\mathrm{CO}_{2}$-rich springs, and

${ }_{11}$ several diffuse degassing areas. The hydrothermal $\mathrm{CO}_{2}$ flux through the soil

12 is continuously recorded by permanent gas stations coupled with several me-

${ }_{13}$ teorological sensors. Daily and seasonal cycles have been observed in the time

${ }_{14}$ series of $\mathrm{CO}_{2}$ flux. Air temperature and barometric pressure are the variables

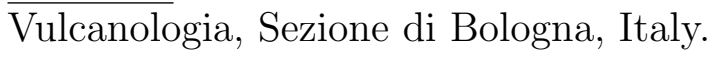

${ }^{2}$ Lawrence Berkeley National Laboratory,

Earth Sciences Division, Berkeley,

California, USA.

${ }^{3}$ ISTerre, CNRS, Université de Savoie,

Chambery, France.

${ }^{4}$ Centro de Vulcanologia e Avaliação de

Riscos Geológicos, Universidade dos Açores,

Portugal. 
${ }_{15}$ that best correlate with the $\mathrm{CO}_{2}$ flux cycles. To understand the influence of

16 atmospheric and soil conditions on the gas emission, several simulations with

${ }_{17}$ TOUGH2 simulator were performed. A simple 1D model was developed to

${ }_{18}$ understand the physical mechanisms producing the observed variations. Then,

19 a dual parameters study focused on how rock permeability and gas source

${ }_{20}$ properties affect the resulting fluxes. Numerical results are in agreement with

${ }_{21}$ the observed data and show that changes in the barometric pressure and air

22 temperature may cause changes in the observed $\mathrm{CO}_{2}$ fluxes, which depend

23 on rock permeability and on pressure driving the upward flux. 


\section{Introduction}

Continuous measurements of carbon dioxide flux are now commonly used to monitor the degassing in volcanic environments [Chiodini et al., 1998, 2010; Hernández et al., 2001].

${ }_{26}$ The transfer of the $\mathrm{CO}_{2}$ to the surface results from two different physical processes, namely ${ }_{27}$ advection and diffusion [e.g. Werner et al., 2000]. Advective transport is mainly induced ${ }_{28}$ by pressure gradient, and by temperature gradients that create density differences. Diffu${ }_{29}$ sion, on the other hand, is controlled by concentration gradients. For both advection and so diffusion processes, the flux depends on the properties of the gas source, on the petrophys31 ical properties of the soil, e.g. permeability, and on the conditions at the surface. In this 32 paper, we aim at modeling how the periodic variations of air temperature and pressure 33 at the soil surface can affect the $\mathrm{CO}_{2}$ flux signals by producing harmonic variations at 34 the same periods. A second goal is to understand if the monitoring of the periodic flux ${ }_{35}$ variations could be used to detect source or medium properties changes. Our model will ${ }_{36}$ be tested on $\mathrm{CO}_{2}$ flux signal recorded at Furnas volcano (Azores, Portugal).

The impact of environmental variables on soil gas emissions has been studied in several 38 degassing areas in the last decades [e.g. Clements and Wilkening, 1974; Reimer, 1980; 39 Klusman and Webster, 1981; Hinkle, 1990, 1994; Chiodini et al., 1998; McGee and Ger40 lach, 1998; McGee et al., 2000; Rogie et al., 2001; Granieri et al., 2003, 2010; Hernández ${ }_{41}$ et al., 2004; Lewicki et al., 2007; Viveiros et al., 2008, 2009; Cigolini et al., 2009]. However very few papers were found in the literature that analyzed diurnal variations for the soil

${ }_{43} \mathrm{CO}_{2}$ flux in hydrothermal environments. Chiodini et al. [1998] noticed that $\mathrm{CO}_{2}$ flux vari${ }_{44}$ ations at Vulcano (Aeolian Islands, Italy) were affected by barometric pressure changes 
${ }_{45}$ rather than by absolute atmospheric pressure value. Granieri et al. [2003] identified a 24

${ }_{46} \mathrm{~h}$ cycle in $\mathrm{CO}_{2}$ fluxes from Solfatara volcano between 1998-2002 and Padrón et al. [2008]

47 recognized diurnal and semidiurnal fluctuations in the gas flux acquired during 2004 in

48 a station located at El Hierro (Canary Islands). On the other side, diurnal and seasonal

${ }_{49}$ variations of $\mathrm{CO}_{2}$ flux derived from soil respiration (biogenic origin) have been intensely

50 studied as $\mathrm{CO}_{2}$ production is dependent on the temperature and the $\mathrm{CO}_{2}$ oscillations are

${ }_{51}$ positively correlated with the air/soil temperature changes [Witkamp, 1969; Bajracharya

${ }_{52}$ et al., 2000; Nakadai et al., 2002], as well as with the wind speed [Takle et al., 2004;

${ }_{53}$ Reicosky et al., 2008; Bowling and Massman, 2011]. Biogenic fluxes are also influenced

${ }_{54}$ by atmospheric pressure [Massman, 2004]. These papers recorded the correlation but did

55 not investigate the processes that cause and explain the observed trends.

${ }_{56}$ Some studies have also recognized periodicities on ${ }^{222} \mathrm{Rn}$ time series in the air [e.g. Rigby ${ }_{57}$ and La Pointe, 1993; Pinault and Baubron, 1997; Robinson et al., 1997; Groves-Kirkby ${ }_{58}$ et al., 2006; Steinitz et al., 2007; Richon et al., 2009] and in the soil [Aumento, 2002;

${ }_{59}$ Richon et al., 2003, 2011; Cigolini et al., 2009]. For example, Clements and Wilkening ${ }_{60}[1974]$ observed that pressure variations of $1 \%-2 \%$ changes the radon flux from $20 \%$ to ${ }_{61} 60 \%$.

${ }_{62}$ This work intends to understand the influence of atmospheric and soil conditions on ${ }_{63}$ the gas release, by performing several simulations with TOUGH2 geothermal simulator ${ }_{64}$ [Pruess et al., 1999]. Although such a simulator is largely used in non-volcanological ${ }_{65}$ contests [e.g. Oldenburg and Rinaldi, 2011; Borgia et al., 2012; Mazzoldi et al., 2012], ${ }_{66}$ applications in volcanology are becoming more common for the study of diffuse degassing ${ }_{67}$ [e.g. Todesco et al., 2010; Chiodini et al., 2010] and of the geophysical and geochemi- 
${ }_{68}$ cal signals related to hydrothermal fluids circulation [e.g. Hutnak et al., 2009; Rinaldi

${ }_{69}$ et al., 2010, 2011]. We used the TOUGH2/EOS2 module to describe $\mathrm{CO}_{2}$ in gas phase

70 fluid. Using a 1D model, a parametric study was performed to understand the physical

${ }_{71}$ mechanisms producing the observed variations. Numerical results, in agreement with the

72 observed data, show that the $\mathrm{CO}_{2}$ fluxes are strongly dependent on reservoir pressure, temperature and pressure changes applied at the surface, and on domain permeability.

\section{A case study: Influence of atmospheric conditions on the $\mathrm{CO}_{2}$ degassing at}

\section{Furnas volcano}

Secondary manifestations of volcanism in the Azores archipelago (Fig. 1) include low

${ }_{75}$ temperature fumaroles (maximum temperature around $100{ }^{\circ} \mathrm{C}$ ), hot and cold $\mathrm{CO}_{2}$-rich

76 springs, and several diffuse degassing areas. Continuous monitoring of hydrothermal soil

${ }_{77} \mathrm{CO}_{2}$ flux begun on Furnas volcano, S. Miguel island, in October 2001, with the installation

78 of a permanent gas station that incorporates several meteorological sensors. Daily and

79 seasonal cycles have been observed in the time series of soil $\mathrm{CO}_{2}$ flux and are coincident

so with the periodical behavior of some meteorological parameters. Statistical analysis ap-

${ }_{81}$ plied to the recorded time series shows that air temperature, barometric pressure, rainfall, and wind speed are the observables that better correlate with the soil $\mathrm{CO}_{2}$ flux variations

${ }_{83}$ [Viveiros et al., 2008, 2009]. These external parameters may also have a different effect

${ }_{84}$ on the gas flux depending on the characteristics of the monitoring site (e.g. physical

${ }_{85}$ properties of the soil, topographic effects, drainage area).

Two permanent soil $\mathrm{CO}_{2}$ flux monitoring stations are presently installed inside Furnas

volcano caldera (S. Miguel Island, Azores archipelago) (Fig. 1). GFUR1 station, which was running between October 2001 and July 2006, was placed in a garden of the Furnas 
${ }_{89}$ thermal baths, close to Furnas village fumarolic field. Average values measured of $\mathrm{CO}_{2}$ flux

90 were $\sim 260 \mathrm{~g} \mathrm{~m}^{-2} \mathrm{~d}^{-1}$ and soil temperature was about $17^{\circ} \mathrm{C}$. The station was reinstalled

${ }_{91}$ (and renamed as GFUR3) in January 2008 closer to Furnas village main fumaroles, in a

${ }_{92}$ thermally anomalous zone where the average soil temperature is $38^{\circ} \mathrm{C}$ at $30 \mathrm{~cm}$ depth,

93 with a soil $\mathrm{CO}_{2}$ flux $\sim 650 \mathrm{~g} \mathrm{~m}^{-2} \mathrm{~d}^{-1}$. A soil $\mathrm{CO}_{2}$ flux station (named GFUR2) was

${ }_{94}$ also installed inside Furnas caldera in the vicinity of Furnas Lake fumarolic ground in

95 October 2004, where soil $\mathrm{CO}_{2}$ flux values around $350 \mathrm{~g} \mathrm{~m}^{-2} \mathrm{~d}^{-1}$ were measured. Soil

96 temperature at this site is $\sim 22{ }^{\circ} \mathrm{C}$ at about $30 \mathrm{~cm}$ of depth. According to Viveiros et al.

${ }_{97}$ [2010], the stations are all installed in diffuse degassing structures (DDS) that are fed by

${ }_{98}$ the hydrothermal sources.

99 The permanent flux stations perform measurements based on the accumulation chamber 100 method [Chiodini et al., 1998]. Every hour, a chamber is lowered on the ground and the 101 gas released at the ground surface is pumped into an infrared gas analyzer (IRGA).

The soil $\mathrm{CO}_{2}$ flux value is computed as the linear best fit of the flux curve during a

\subsection{Spectral analysis applied to $\mathrm{CO}_{2}$ flux data at GFUR2}


111 registered at station GFUR2 during the summers of the whole period (2005 - 2009, from

${ }_{112}$ May to September), since, in that period of the year, average monthly rainfall is low, and ${ }_{113}$ then rainfall effects on degassing can be considered as negligible. In addition, GFUR2 is 114 the monitoring site with longer register at Furnas volcano.

${ }_{115}$ The magnitude of the diurnal variations on the soil $\mathrm{CO}_{2}$ flux (usually from 50 to 100 ${ }_{116} \mathrm{~g} \mathrm{~m}^{-2} \mathrm{~d}^{-1}$ ) excludes the possibility of a biogenic origin of the $\mathrm{CO}_{2}$ variations. Works ${ }_{117}$ published in biogenic environments [e.g. Nakadai et al., 2002] refer significantly lower ${ }_{118}$ daily amplitudes (about $5-6 \mathrm{~g} \mathrm{~m}^{-2} \mathrm{~d}^{-1}$ ), indicating that the site of the present study at ${ }_{119}$ Furnas are clearly fed by volcanic-hydrothermal sources.

Diurnal and semi-diurnal components are observed in the soil $\mathrm{CO}_{2}$ flux time series (Fig. 
134 
179

\subsection{Furnas case}


${ }_{201}$ be inversely correlated to both air temperature (red line) and pressure (black line). The 
224 to the average temperature of the whole system, and clearly alter the initial temperature

226 density (Fig. 6e,f).

\section{Comparison between harmonic flux changes in model and observations}

\subsection{Power spectra}




\section{Effect of permeability and source pressure on $12 \mathrm{~h}$ and $24 \mathrm{~h} \mathrm{CO}_{2}$ flux}

\section{components}

In this section, a two parameters study will be presented. The changes in peak amplitude in the spectrum and time delay of the $24 \mathrm{~h}$ and $12 \mathrm{~h}$ components of the flux variations will be analyzed as a function of the rock permeability and the gas reservoir overpressure. Domain permeability ranges between $10^{-15} \mathrm{~m}^{2}$ and $10^{-11} \mathrm{~m}^{2}$, and gas reservoir overpressure between $2 \cdot 10^{-5}$ and $0.1 \mathrm{MPa}$.

The first set of simulations was run changing the rock permeability and keeping a constant gas reservoir overpressure as in the base case $(0.05 \mathrm{MPa}$, a value that is consistent with observed gas flux). The resulting changes in peak amplitude and time delay are shown in Figure 9. The peak amplitude of the simulated $\mathrm{CO}_{2}$ flux always presents both the $12 \mathrm{~h}$ and $24 \mathrm{~h}$ component (Fig. 9a, green and blue lines, respectively). However, the two analyzed components are not always comparable. The $24 \mathrm{~h}$ component is dominant for most of the considered permeabilities. More than one order of magnitude differences between $24 \mathrm{~h}$ and $12 \mathrm{~h}$ components appear for low permeabilities. This difference decreases at higher permeability, and the two considered components have the same order of magnitude for the highest permeability considered $\left(10^{-11} \mathrm{~m}^{2}\right)$. Results also show changes in time delay (Fig. 9b). The $24 \mathrm{~h}$ component of the $\mathrm{CO}_{2}$ flux has a delay with respect the temperature perturbation ranging between 18 hours and 14 hours (Fig. 9b, blue line). The higher the permeability, the lower the delay observed. The delay of the $12 \mathrm{~h}$ component of the $\mathrm{CO}_{2}$ flux with respect to the pressure perturbation is rather constant $(\sim$ ${ }^{34} 6$ hours) for most of the simulated permeabilities, and increases up to 8 hours only for permeability lower than $10^{-14} \mathrm{~m}^{2}$ (Fig. 9b, green line). 
${ }_{286}$ The second set of simulations was run keeping a constant rock permeability, set as in the base case $\left(2 \cdot 10^{-14} \mathrm{~m}^{2}\right)$, and changing the overpressure at the base of the domain. Figure 10 shows the changes in peak amplitude and time delay as a function of the gas reservoir 
309 11a), and reaches a maximum of 8 hours only for very low permeability $\left(10^{-15} \mathrm{~m}^{2}\right)$. The 
332 is mainly influenced by permeability rather than source pressure changes. A similar, but

333 less marked, pattern is observed in Figure 11d for the amplitude of the $24 \mathrm{~h}$ component.

Analyzing the changes in $24 \mathrm{~h}$ and $12 \mathrm{~h}$ peak in the spectrum, a change in soil permeability

342 a permeability change from a pressure change.

343

\section{Discussion and Conclusion}


${ }_{361}$ during the afternoon.

362 
387 or declining trends.

${ }_{388}$ Applied perturbations and simulated gas flow changes are not only confined at the 
399 the same order of magnitude of the observed changes at Furnas. We calculated two time 
These results indicate that a coupled analysis of these observables may provide useful hints to discriminate the parameter that is changing within the system. According to ${ }_{424}$ our model, the observation of correlated changes in the diurnal and semi-diurnal components of diffuse degassing, under the conditions described above, would be related to a permeability change in the soil. On the contrary, an unrelated evolution of these components would indicate a change in the source conditions. This is in agreement with the ${ }_{428}$ observations of Richon et al. [2003] that correlated changes in the $12 \mathrm{~h}$ cycle of $\mathrm{Rn}$ time ${ }_{429}$ series with a magnitude 7.1 earthquake close to Taal volcano (Philippines). Permeability ${ }_{430}$ changes in a volcano/hydrothermal system can be generated by transient stresses, includ${ }_{431}$ ing distant earthquakes [Elkhoury et al., 2006; Manga et al., 2012], or may result from ${ }_{432}$ micro-fracturing associated with intrusive processes and mechanical disturbances, such as ${ }_{433}$ a dome collapse, or from mineral dissolution or precipitation [White and Mroczek, 1998].

${ }_{434}$ The monitoring of harmonic components of the gas flux signal should thus be integrated ${ }_{435}$ in volcano monitoring as it represents a tool to understand the reasons of gas flux changes ${ }_{436}$ at the surface.

Acknowledgments. This work was carried out when the first author was enrolled in ${ }_{438}$ the Doctorate school at the University of Bologna, on a grant funded by the Istituto ${ }_{439}$ Nazionale di Geofisica e Vulcanologia - Sezione di Bologna. A. P. Rinaldi is currently sup${ }_{440}$ ported by DOE-LBNL contract number DE-AC02-05CH11231. F. Viveiros is supported ${ }_{441}$ by a Postdoc grant from Fundo Regional da Ciência e Tecnologia. 


\section{References}

${ }_{442}$ Aumento, F. (2002), Radon tides on an active volcanic island: Terceira, Azores, Geof.

${ }_{443} \quad$ Int., $41(4), 499-505$.

${ }_{444}$ Bajracharya, R. M., R. Lal, and J. N. Kimble (2000), Diurnal and seasonal $\mathrm{CO}_{2}-\mathrm{C}$ flux

${ }_{445}$ from soil as related to erosion phases in central Ohio, Soil Sci. Soc. Am. J., 64, 286-293.

Borgia, A., K. Pruess, T. J. Kneafsey, C. M. Oldenburg, and L. Pan (2012), Numerical simulation of salt precipitation in the fractures of a $\mathrm{CO}_{2}$-enhanced geothermal system, Geothermics, 44, 13-22, doi:10.1016/j.geothermics.2012.06.002. 
${ }_{464}$ Granieri, D., G. Chiodini, W. Marzocchi, and R. Avino (2003), Continuous monitoring of

$\mathrm{CO}_{2}$ soil diffuse degassing at Phlegrean Fields (Italy): influence of environmental and volcanic parameters, Earth Planet. Sci. Lett., 212, 167-179.

Granieri, D., R. Avino, and G. Chiodini (2010), Carbon dioxide diffuse emission from the soil: ten years of observations at Vesuvio and Campi Flegrei (Pozzuoli), and linkages with volcanic activity, Bull. Volcanol., 72, 103-118, doi:10.1007/s00445-009-0304-8.

Groves-Kirkby, C. J., A. R. Denman, R. G. M. Crockett, P. S. Phillips, and G. K. Gillmore (2006), Identification of tidal and climatic influences within domestic radon time-series from Northamptonshire, UK, Sci. Total Environ., 367, 191-202.

Hernández, P., N. Pérez, J. Salazar, M. Reimer, K. Notsu, and H. Wakita (2004), Radon and helium in soil gases at Canãdas Caldera, Tenerife, Canary Islands, Spain, J. Volcanol. Geotherm. Res., 131, 59-76.

Hernández, P. A., et al. (2001), Carbon Dioxide Degassing by Advective Flow from Usu Volcano, Japan, Science, 292, 83, doi:10.1126/science.1058450.

Hinkle, M. E. (1990), Factors affecting concentrations of helium and carbon dioxide in soil gases, in Geochemistry of gaseous elements and compounds, edited by E. M. Durrance, E. M. Galimov, M. E. Hinkle, G. M. Reimer, R. Sugisaki, and S. S. Augustithis, pp. 421-448, Theophrastus Publications, S. A.

Hinkle, M. E. (1994), Environmental conditions affecting $\mathrm{He}, \mathrm{CO}_{2}, \mathrm{O}_{2}$, and $\mathrm{N}_{2}$ in soil gases, Appl. Geochem., 9, 53-63.

Hutnak, M., S. Hurwitz, S. E. Ingebritsen, and P. A. Hsieh (2009), Numerical models of caldera deformation: Effects of multiphase and multicomponent hydrothermal fluid flow, J. Geophys. Res., 114, B04411, doi:10.1029/2008JB006151. 
Klusman, R. W., and J. D. Webster (1981), Preliminary analysis of meteorological and seasonal influences on crustal gas emission relevant to earth prediction, Bull. Seism. Soc. Am., $71(1), 211-222$.

Lewicki, J. L., G. E. Hilley, T. Tosha, R. Aoyagi, K. Yamamoto, and S. M. Benson (2007), Dynamic coupling of volcanic $\mathrm{CO}_{2}$ flow and wind at the Horseshoe Lake tree kill, Mammoth Mountain, California, Geophys. Res. Lett., 34, L03401, doi: 10.1029/2006GL028848.

Manga, M., I. Beresnev, E. E. Brodsky, J. E. Elkhoury, D. Elsworth, S. E. Ingebritsen, D. C. Mays, and C.-Y. Wang (2012), Changes in permeability caused by transient stresses: Field observations, experiments, and mechanisms, Re. Geophys., 50, RG2004, doi:10.1029/2011RG000382.

Massman, W. J. (2004), Advective transport of $\mathrm{CO}_{2}$ in permeable media induced by atmospheric pressure fluctuations: 1. An analytical model, J. Geophys. Res., 111, G03004.

Mazzoldi, A., A. P. Rinaldi, A. Borgia, and J. Rutqvist (2012), Induced seismicity within GCS projects: maximum earthquake magnitude and leakage potential from undetected faults, Int. J. Greenhouse Gas Control, submitted.

McGee, K. A., and T. M. Gerlach (1998), Annual cycle of magmatic $\mathrm{CO}_{2}$ in a tree-kill soil at Mammoth Mountain, California: Implications for soil acidification, Geology, 26(5), $463-466$.

McGee, K. A., T. M. Gerlach, R. Kessler, and M. P. Doukas (2000), Geochemical evidence for a magmatic $\mathrm{CO}_{2}$ degassing event at Mommoth Mountain, California, SeptemberOctober 1997, J. Geophys. Res., 105, 8447-8456. 

dioxide flux from bare soil in agricultural field in Japan, App. Soil Ecol., 19, 161-171.

Oldenburg, C. M., and A. P. Rinaldi (2011), Buoyancy Effects on Upward Brine Displacement Caused by $\mathrm{CO}_{2}$ Injection, Transp. Porous Med., 87, 525 - 540, doi:10.1007/s11242010-9699-0.

Padrón, E., P. A. Hernández, T. Toulkeridis, N. M. Pérez, R. Marrero, F. Melián, G. Virgili, and K. Notsu (2008), Diffuse $\mathrm{CO}_{2}$ emission rate from Pululahua and the lake-filled Cuicocha calderas, Ecuador, J. Volcanol. Geotherm. Res., 176, 163-169.

Pinault, J. L., and J. C. Baubron (1997), Signal processing of diurnal and semidiurnal variations in radon and atmospheric pressure: A new tool for accurate in situ measurement of soil gas velocity, pressure gradient, and tourtuosity., J. Geophys. Res., 102(B8), $18,101-18,120$.

Pruess, K., C. M. Oldenburg, and G. Moridis (1999), TOUGH2 user's guide, version 2.0, Paper LBNL-43134., Lawrence Berkeley Natl. Lab., Berkeley, CA, USA.

Reicosky, D. C., R. W. Gesch, S. W. Wagner, R. A. Gilbert, C. D. Wente, and D. R. Morris (2008), Tillage and wind effects on soil $\mathrm{CO}_{2}$ concentrations in muck soils, Soil $\&$ Tillage Research, 99, 221-231.

Reimer, G. M. (1980), Use of Soil-Gas Helium Concentrations for Earthquake prediction: Limitations Imposed by Diurnal Variation, J. Geophys. Res., 85(B6), 3107-3115, doi: 10.1029/JB085iB06p03107.

Richon, P., J. C. Sabroux, M. Halbwachs, J. Vandemeulebrouck, N. Poussielgue, J. Tabbagh, and R. Punongbayan (2003), Radon anomaly in the soil of Taal volcano, the Philippines: A likely precursor of the M7.1 Mindoro earthquake (1994)., Geophys. Res. 
Lett., 30 (9), 1481, doi:10.1029/2003GL016902.

Richon, P., F. Perrier, E. Pili, and J. C. Sabroux (2009), Detectability and significance of $12 \mathrm{hr}$ barometric tide in radon-222 signal, dripwater flow rate, air temperature and carbon dioxide concentration in an underground tunnel, Geophys. J. Int., 176, 683-694, doi:10.1111/j.1365-246X.2008.04000.x.

Richon, P., F. Perrier, B. P. Koirala, F. Girault, M. Bhattarai, and S. N. Sapkota (2011), Temporal signatures of advective versus diffusive radon transport at a geothermal zone in Central Nepal, J. Environ. Radioactivity, 102(2), 88 - 102, doi: 10.1016/j.jenvrad.2010.10.005.

Rigby, J. G., and D. D. La Pointe (1993), Wind and barometric pressure effects on Radon in two mitigated houses, The 1993 International Radon Conference, pp. 61-68.

Rinaldi, A. P., M. Todesco, and M. Bonafede (2010), Hydrothermal instability and ground displacement at the Campi Flegrei caldera, Phys. Earth Planet. Int., 178, 155-161, doi: 10.1016/j.pepi.2009.09.005.

Rinaldi, A. P., M. Todesco, J. Vandemeulebrouck, A. Revil, and M. Bonafede (2011), Electrical conductivity, ground displacement, gravity changes, and gas flow at Solfatara crater (Campi Flegrei caldera, Italy): results from numerical modeling, J. Volcanol. Geotherm. Res., 207, 93 - 105, doi:10.1016/j.jvolgeores.2011.07.008.

Robinson, A. L., R. G. Sextro, and W. J. Riley (1997), Soil-gas entry into houses driven by atmospheric pressure fluctuations - The influence of soil properties, Atmos. Environ., $31(10), 1487-1495$.

Rogie, J. D., D. M. Kerrick, M. L. Sorey, G. Chiodini, and D. L. Galloway (2001), Dynamics of carbon dioxide emission at Mammoth Mountain, California, Earth Planet. 
Sci. Lett., 188, 535-541.

Steinitz, G., O. Piatibratova, and S. M. Barbosa (2007), Annual cycle of magmatic $\mathrm{CO}_{2}$ in a tree-kill soil at Mammoth Mountain, California: Implications for soil acidification, J. Geophys. Res., 112, B10211, doi:10.1029/2006JB004817.

Takle, E. S., W. J. Massman, J. R. Brandle, R. A. Schmiat, X. Zhou, I. V. Litvina, R. Garcia, G. Doyle, and C. W. Rice (2004), Influence of high-frequency ambient pressure pumping on carbon dioxide efflux from soil, Agric. Forest Meteor., 124, 193-206.

Todesco, M., A. P. Rinaldi, and M. Bonafede (2010), Modeling of unrest signals in heterogeneous hydrothermal systems, J. Geophys. Res., 115, B09213, doi: 10.1029/2010JB007474.

Viveiros, F., T. Ferreira, J. Cabral Vieira, C. Silva, and J. L. Gaspar (2008), Environmental influences on soil $\mathrm{CO}_{2}$ degassing at Furnas and Fogo volcanoes (São Miguel Island, Azores archipelago), J. Volcanol. Geotherm. Res., 177, 883-893.

Viveiros, F., T. Ferreira, C. Silva, and J. L. Gaspar (2009), Meteorological factors controlling soil gases and indoor $\mathrm{CO}_{2}$ concentration: a permanent risk in degassing areas, Sci. Total Environ., 407, 1362-1372.

Viveiros, F., C. Cardellini, T. Ferreira, S. Caliro, G. Chiodini, and C. Silva (2010), Soil $\mathrm{CO}_{2}$ emissions at Furnas volcano, São Miguel Island, Azores archipelago: Volcano monitoring perspectives, geomorphologic studies, and land use planning application, J. Geophys. Res., 115, B12208, doi:10.1029/2010JB007555.

Werner, C., S. L. Brantley, and K. Boomer (2000), $\mathrm{CO}_{2}$ emission related to the Yellowstone volcanic system 2. Statistical sampling, total degassing, and transport mechanisms, J. Geophys. Res, 105(B5), 10,831-10,846. 
${ }_{578}$ White, S. P., and E. K. Mroczek (1998), Permeability Changes During the Evolution of a Geothermal Field Due to the Dissolution and Precipitation of Quartz, Trans. Porous ${ }_{580} \quad$ Med., 33, 81-101, doi:10.1023/A:1006541526010.

${ }_{581}$ Witkamp, M. (1969), Environmental effects on microbial turnover of some mineral ele${ }_{582}$ ments: Part II-Biotic factors, Soil Biol. Biochem., 1 (3), 177 - 184, doi:10.1016/00380717(69)90017-0. 
Table 1. Correlation and time delay between each of the meteorological variables and the soil $\mathrm{CO}_{2}$ flux at GFUR2 for the summer period.

\begin{tabular}{|c|c|c|c|c|}
\hline & \multicolumn{2}{|c|}{ Corr. $(r)$} & \multicolumn{2}{|c|}{ Delay (h) } \\
\hline & $24 \mathrm{~h}$ comp. & 12h comp. & $24 \mathrm{~h}$ comp. & $12 \mathrm{~h}$ comp. \\
\hline Air humidity & 0.880 & 0.686 & $0 \mathrm{~h}$ & $0 \mathrm{~h}$ \\
\hline Air temperature & 0.890 & 0.721 & $11 \mathrm{~h}$ & $\sim 6 \mathrm{~h}$ \\
\hline Barometric pressure & 0.533 & 0.683 & $\sim 6 \mathrm{~h}$ & $\sim 4 \mathrm{~h}$ \\
\hline Wind speed & 0.904 & 0.727 & $10 \mathrm{~h}$ & $\sim 6 \mathrm{~h}$ \\
\hline
\end{tabular}


Table 2. Governing equations solved in TOUGH2/EOS2 for single-phase, singlecomponent $\left(\mathrm{CO}_{2}\right)$ non-isothermal cases. Symbols: $V$ volume $\left(\mathrm{m}^{3}\right), M$ mass accumulation term $\left(\mathrm{kg} \mathrm{m}^{-3}\right), \Gamma$ surface area $\left(\mathrm{m}^{2}\right), \mathbf{F}$ Darcy flux vector $\left(\mathrm{kg} \mathrm{m}^{2} \mathrm{~s}^{-1}\right), \mathbf{n}$ outward unit normal vector, $q_{V}$ volumetric source term $\left(\mathrm{kg} \mathrm{m}^{-3} \mathrm{~s}^{-1}\right), \phi$ porosity, $\rho$ and $\rho_{R}$ fluid and rock density $\left(\mathrm{kg} \mathrm{m}^{-3}\right), C_{R}$ heat capacity of the rock formation $\left(\mathrm{J} \mathrm{kg}^{-1} \mathrm{~K}^{-1}\right), T$ temperature, $u_{\mathrm{CO}_{2}}$ internal energy $\left(\mathrm{J} \mathrm{kg}^{-1}\right), \kappa$ permeability $\left(\mathrm{m}^{2}\right), \mu$ dynamic viscosity $\left(\mathrm{kg} \mathrm{m}^{-1} \mathrm{~s}^{-1}\right)$, $P$ total pressure $(\mathrm{Pa}), \lambda$ thermal conductivity $\left(\mathrm{J} \mathrm{s}^{-1} \mathrm{~m}^{-1} \mathrm{~K}^{-1}\right), h_{\mathrm{CO}_{2}}$ enthalpy $\left(\mathrm{J} \mathrm{kg}^{-1}\right)$. Equations are generally solved for each component and the heat "component". In this case we only consider a component, then the heat is considered as second component (superscript 2)

Description

Conservation of mass and energy

Mass accumulation

Thermal energy accumulation

Phase flux

Thermal energy flux

\section{Equation}

$$
\begin{aligned}
& \frac{\mathrm{d}}{\mathrm{dt}} \int_{V_{n}} M \mathrm{dV}=\int_{\Gamma_{n}} \mathbf{F} \cdot \mathbf{n} \mathrm{d} \Gamma+\int_{V_{n}} q_{V} \mathrm{dV} \\
& M=\phi \rho \\
& M^{(2)}=(1-\phi) \rho_{R} C_{R} T+\phi \rho u_{C O_{2}} \\
& \mathbf{F}=-\kappa \frac{\rho}{\mu}(\nabla P-\rho \mathbf{g}) \\
& \mathbf{F}^{(2)}=-\lambda \nabla T+h_{\mathrm{CO}_{2}} \mathbf{F}
\end{aligned}
$$



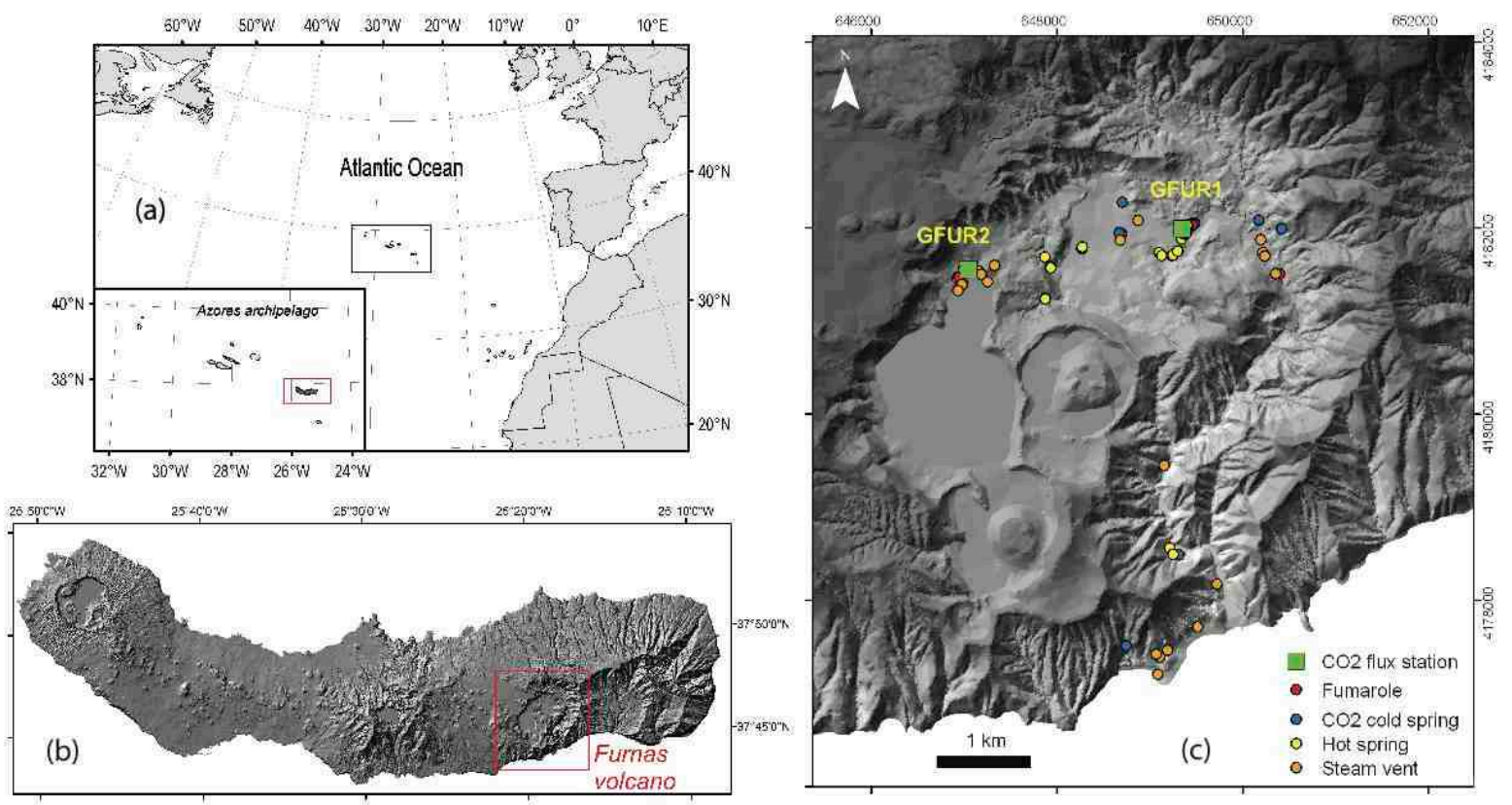

Figure 1. (a) Azores archipelago location highlighting S. Miguel Island; (b) Digital Elevation Model of the S. Miguel Island; (c) Hydrothermal manifestations and location of the permanent soil $\mathrm{CO}_{2}$ stations at Furnas volcano. 


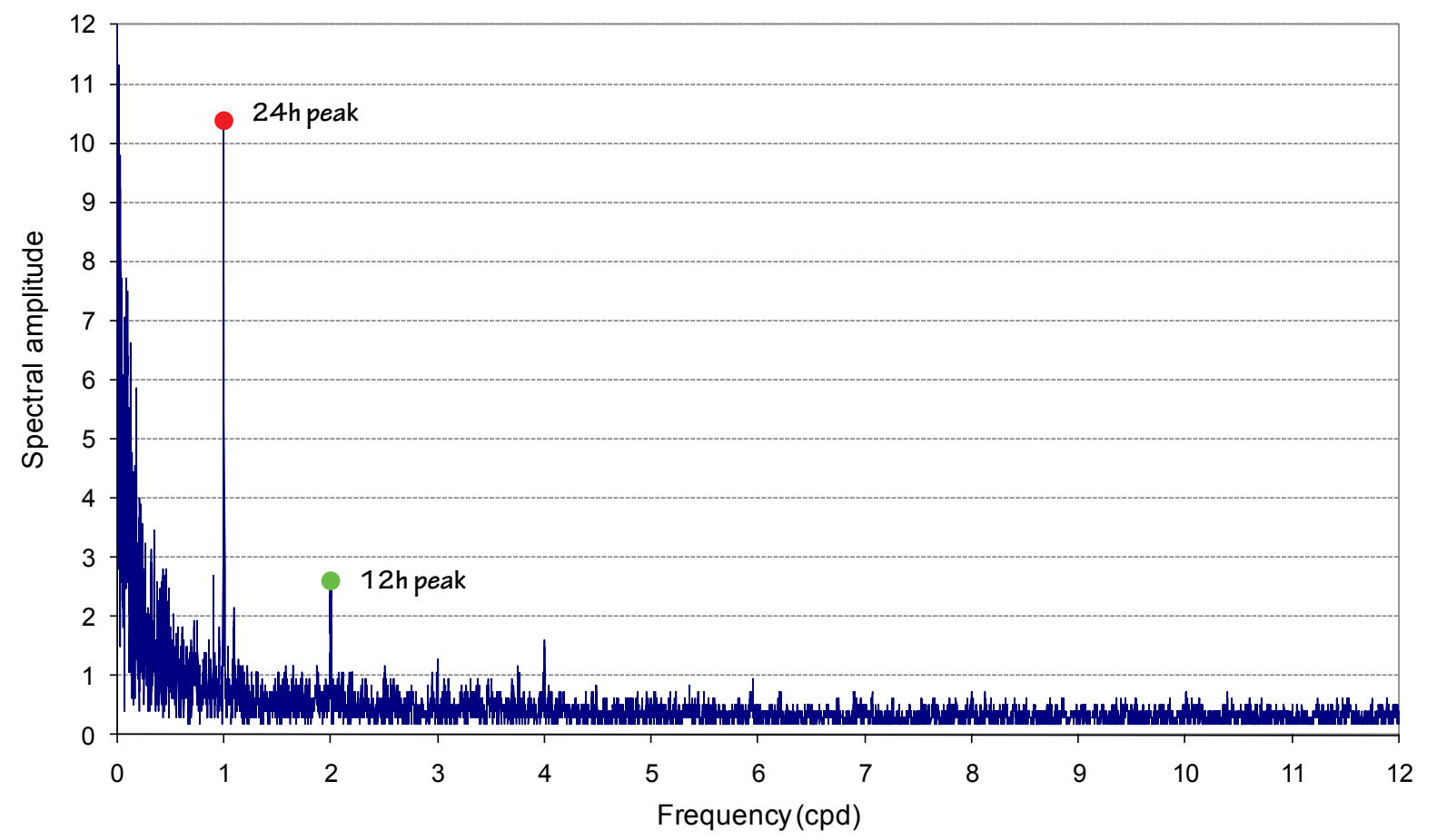

Figure 2. Amplitude spectrum of the soil $\mathrm{CO}_{2}$ flux recorded at GFUR2 during summer months (2005-2009, from May to September). Red dot indicates the 24h peak (1 cpd). Green dot indicates the $12 \mathrm{~h}$ peak $(2 \mathrm{cpd}) .(\mathrm{cpd}=$ cycles per day $)$ 


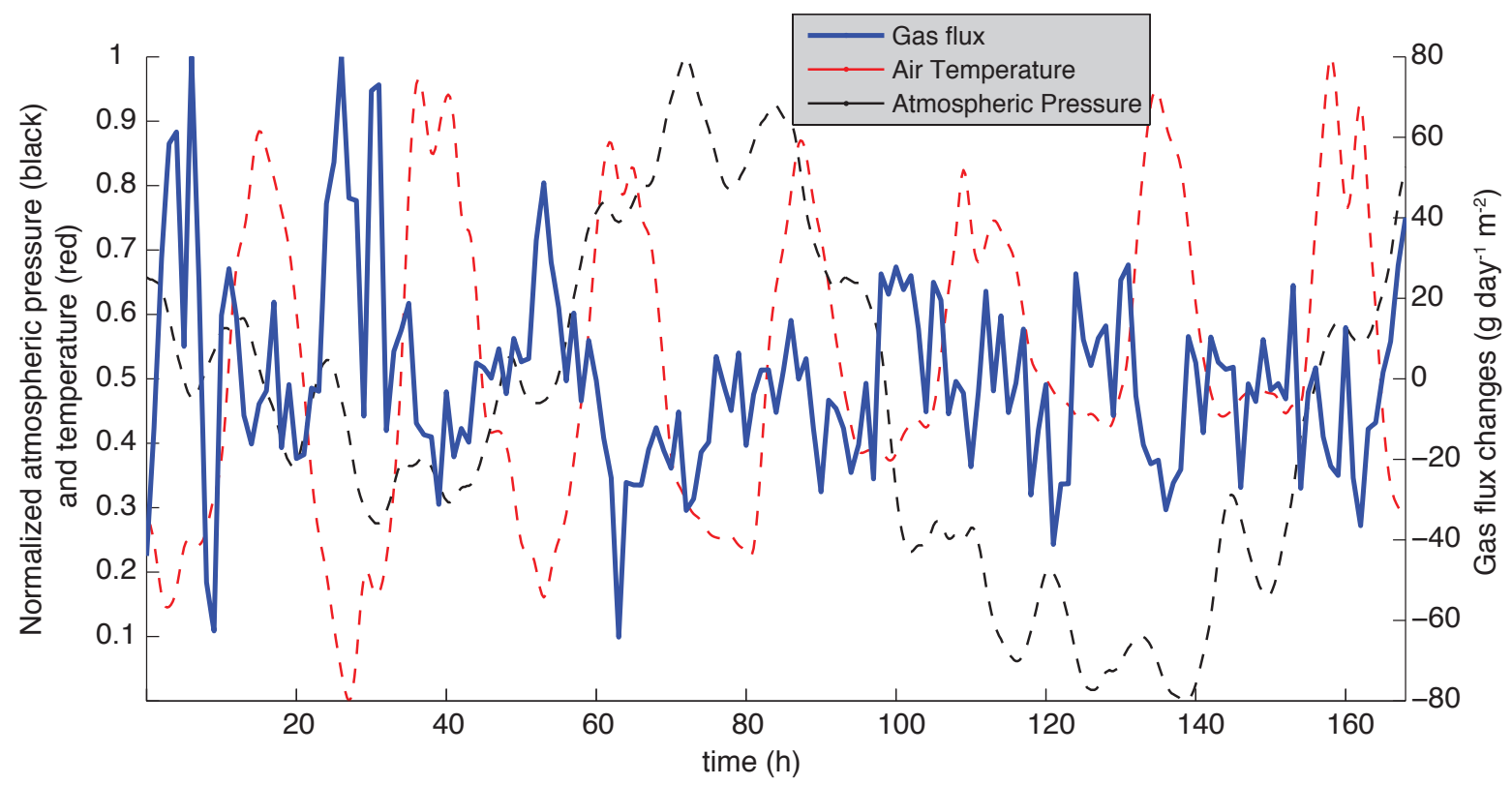

Figure 3. Example of atmospheric and $\mathrm{CO}_{2}$ flux signals observed at GFUR2 station in a week of summer (7/9/2005-7/15/2005): air temperature (red, dashed), barometric pressure (black, dashed), and variations around the average $\mathrm{CO}_{2}$ flux (blue, solid). Temperature and pressure are normalized in this figure. 


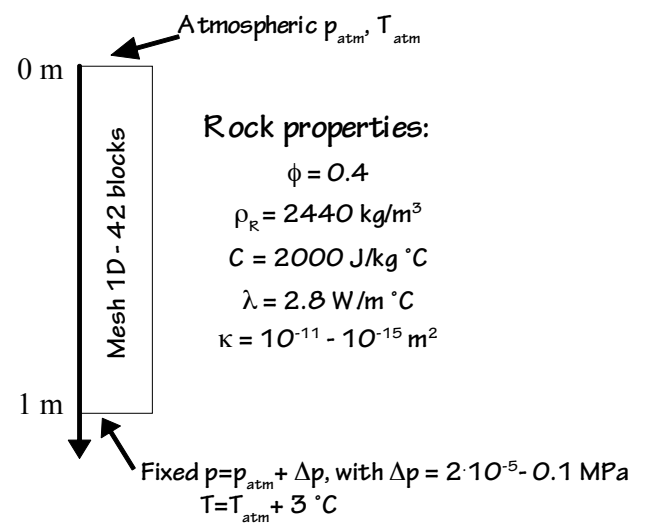

Figure 4. Numerical 1D domain and rock properties. $\phi$ is the porosity, $\rho_{R}$ is the rock density, $C$ is the specific heat, and $\lambda$ is the thermal conductivity. These properties were kept constant during all the simulations. $\kappa$ is the range of variation for the rock permeability. Atmospheric pressure and temperature depend on the considered simulation. For steady-state, initial conditions are $T_{\mathrm{atm}}=17.5^{\circ} \mathrm{C}$ and $p_{\mathrm{atm}}=0.09927 \mathrm{MPa} . \Delta p$ at the bottom is the range of variation for the reservoir overpressure. Pressure and temperature within the gas reservoir $\left(p=p_{\text {atm }}+\Delta p\right.$ and $\left.T=T_{\text {atm }}+3\right)$ are fixed during a single simulation as the initial steady-state condition, and do not change as $p_{\text {atm }}$ and $T_{\text {atm }}$ evolve in time. 

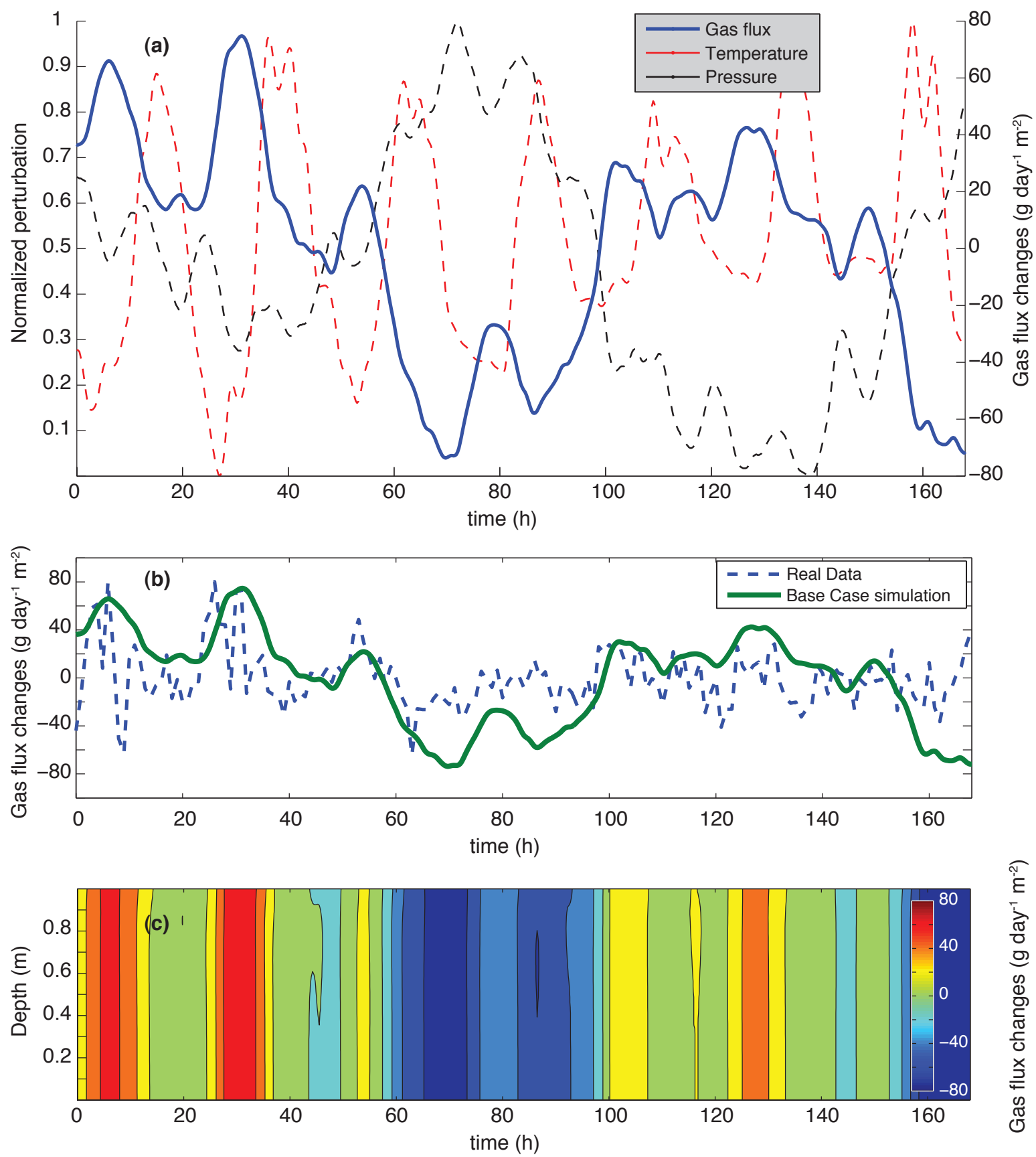

Figure 5. (a) Simulated temporal $\mathrm{CO}_{2}$ flux changes (blue line) at the surface due to the application of both atmospheric pressure (black line) and temperature (red line) weekly variation. For this base case permeability $\kappa=2 \cdot 10^{-14} \mathrm{~m}^{2}$ and reservoir overpressure $\Delta p=0.05 \mathrm{MPa}$ were considered. (b) Comparison with the real flux changes (blue line) observed at station GFUR2 at Furnas. (c) $\mathrm{CO}_{2}$ changes in time and depth. D R A F T August 30, 2012, 9:29am $\quad$ D R A F T 

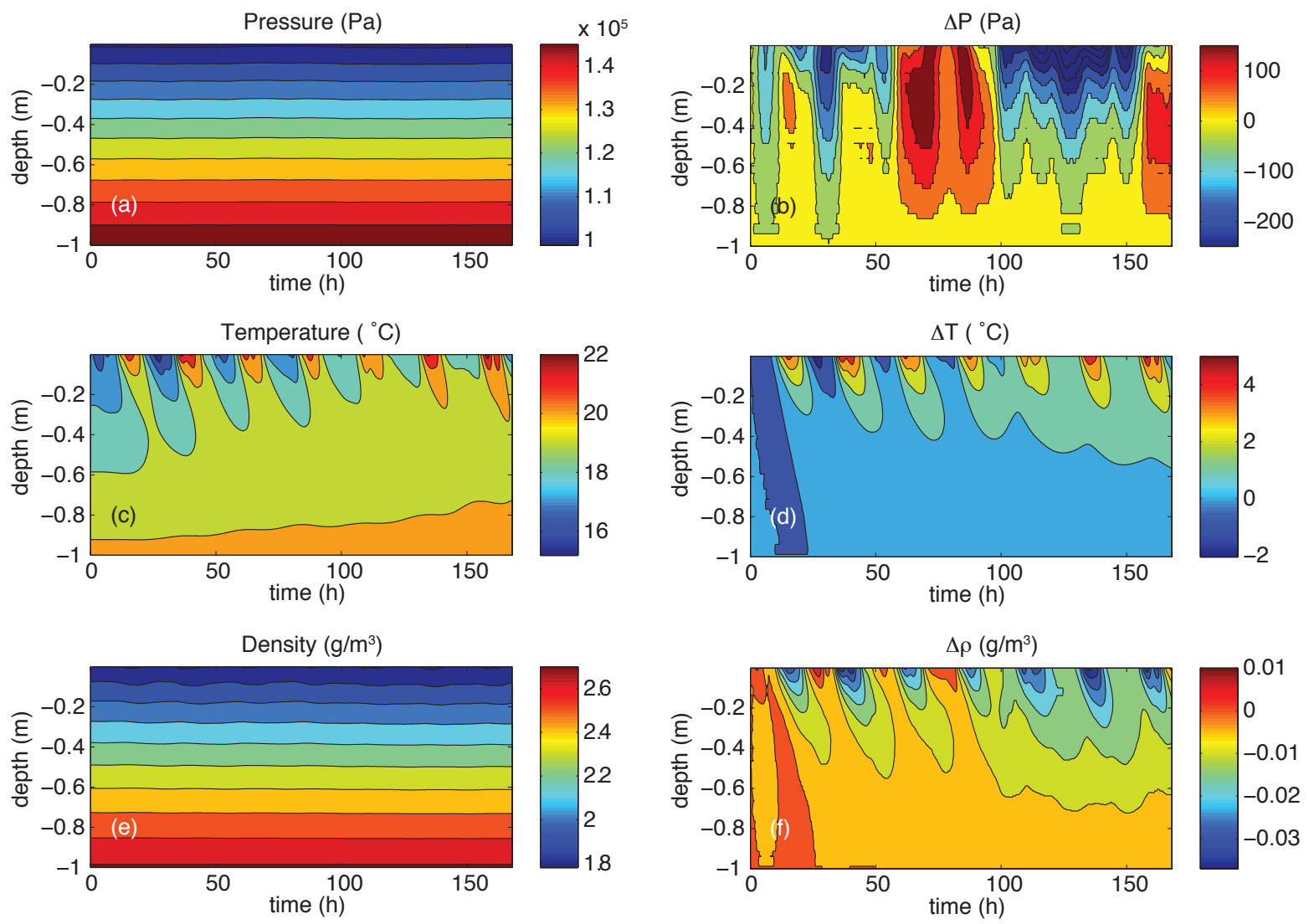

Figure 6. (a,c,e) Pressure, temperature and gas density in time and depth for the base case simulation. $(\mathbf{b}, \mathbf{d}, \mathbf{f})$ Variation of $p, T$, and $\rho$ in time and depth with respect to the initial steady state condition. 

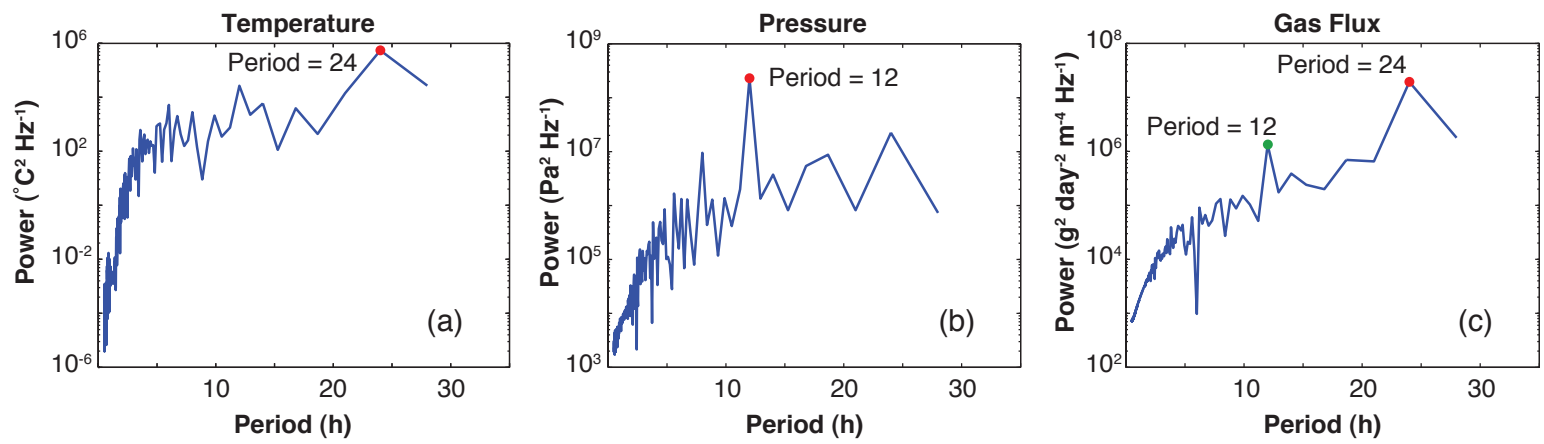

Figure 7. Low-pass filtered spectra for temperature (a), pressure (b), and simulated gas flux (c): all the periods larger than $28 \mathrm{~h}$ are have been filtered. Red dot indicates the main peak for each time series. 

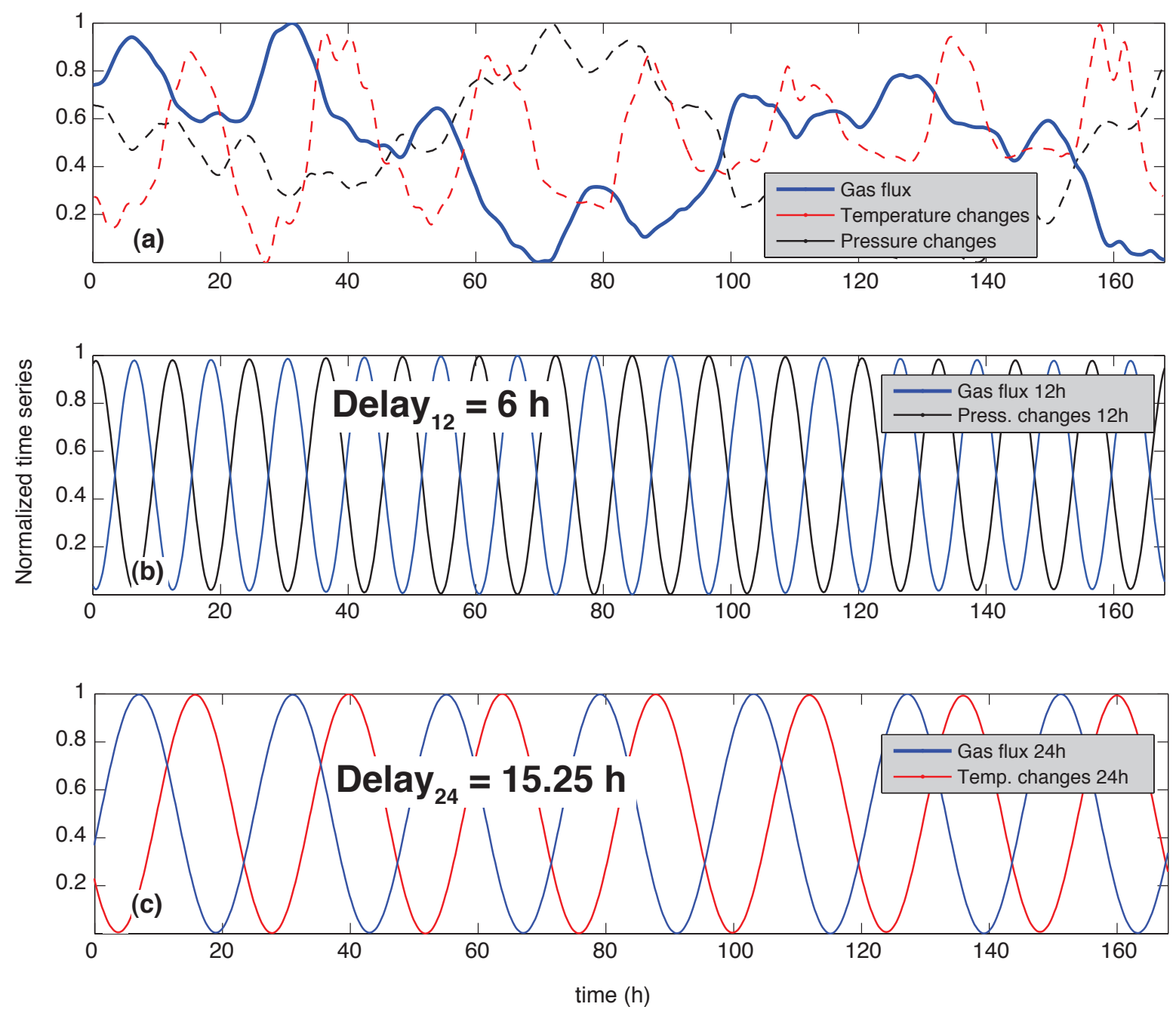

Figure 8. (a) Normalized time series: pressure (black), temperature (red), and simulated gas flux (blue). (b) Normalized and filtered time series for the $12 \mathrm{~h}$ component: pressure (black) and simulated gas flux (blue). $\mathrm{CO}_{2}$ flux is 6 hours delayed with respect to the pressure time series. (c) Normalized and filtered time series for the $24 \mathrm{~h}$ component: temperature (black) and simulated gas flux (blue). $\mathrm{CO}_{2}$ flux is 15.25 hours delayed with respect to the temperature time series. 

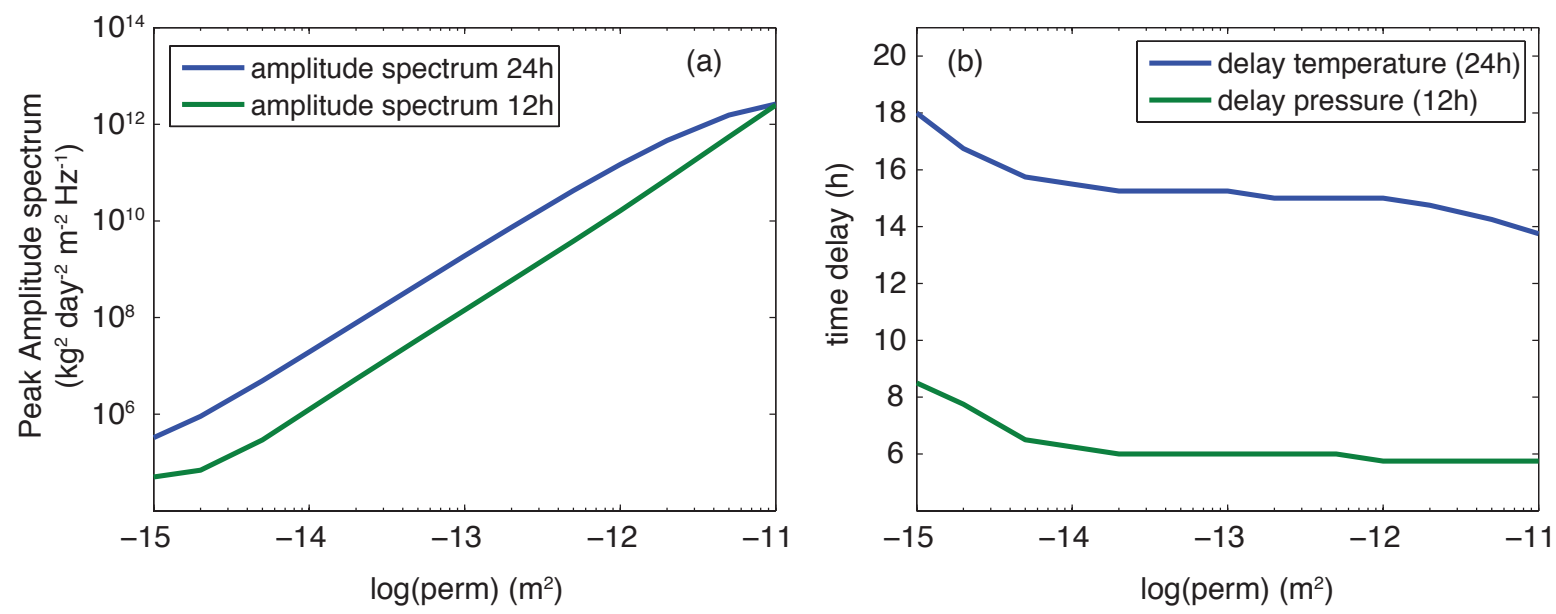

Figure 9. (a) Peak amplitude in the spectrum of the $\mathrm{CO}_{2}$ flux as a function of the domain permeability for the $12 \mathrm{~h}$ (green line) and $24 \mathrm{~h}$ (blue line) component, respectively. (b) Time delay as a function of the domain permeability, with respect the pressure (12h component, green line) and temperature (24h component, blue line), respectively. For this set of simulations reservoir overpressure was fixed as in the base case (0.05 MPa). 

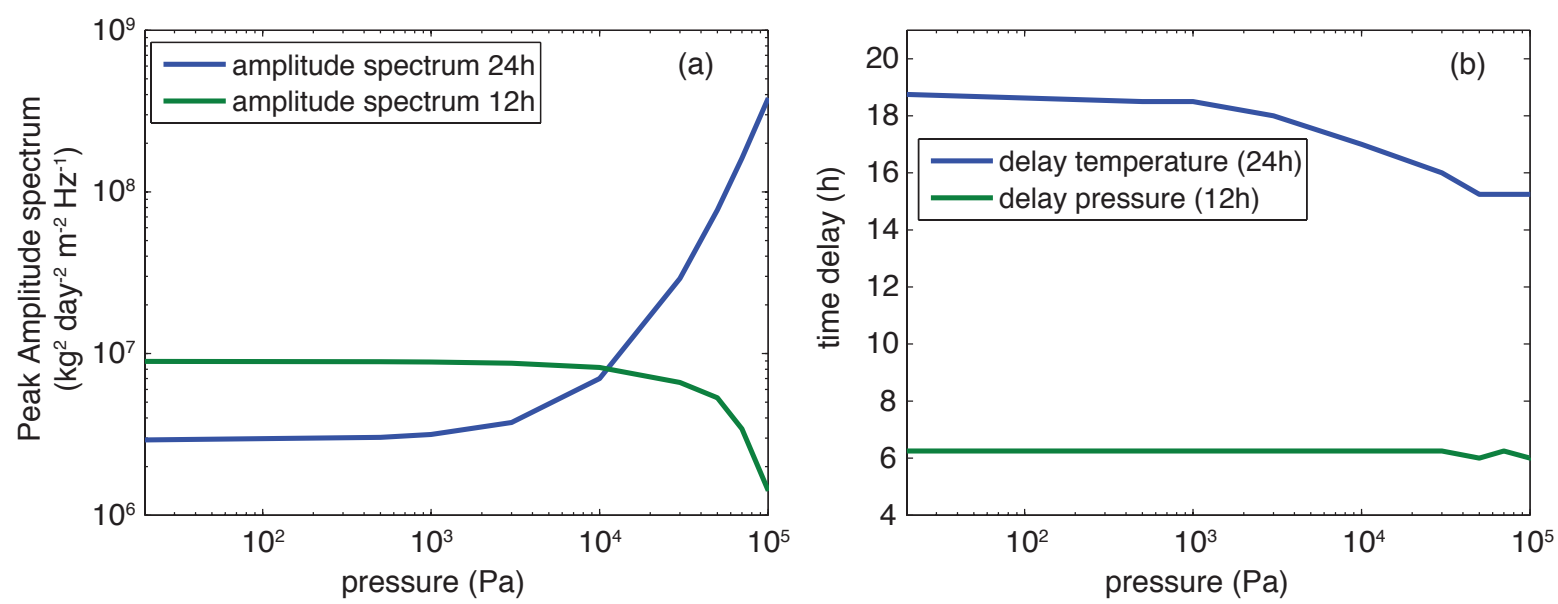

Figure 10. (a) Peak amplitude in the spectrum of the $\mathrm{CO}_{2}$ flux as a function of the reservoir overpressure for the $12 \mathrm{~h}$ (green line) and $24 \mathrm{~h}$ (blue line) component, respectively. (b) Time delay as a function of the reservoir overpressure, with respect the pressure $(12 \mathrm{~h}$ component, green line) and temperature (24h component, blue line), respectively. For this set of simulations domain permeability was fixed as in the base case $\left(2 \cdot 10^{-14} \mathrm{~m}^{2}\right)$. 


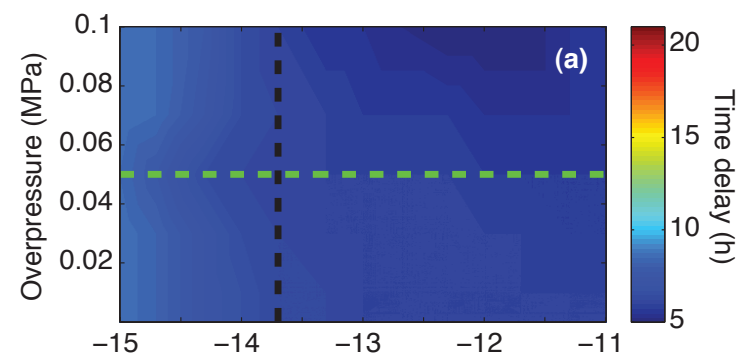

Log (permeability) $\left(\mathrm{m}^{2}\right)$

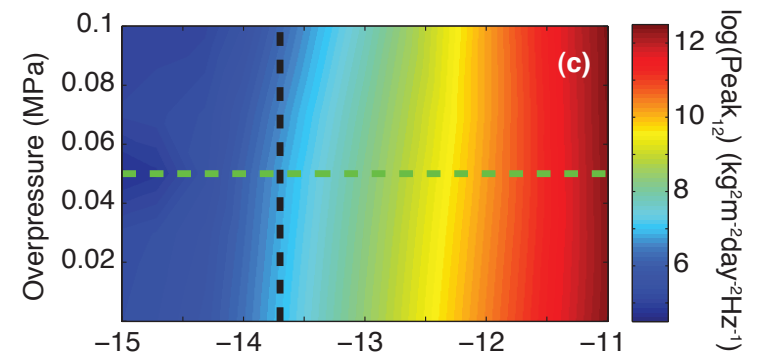

Log (permeability) $\left(\mathrm{m}^{2}\right)$

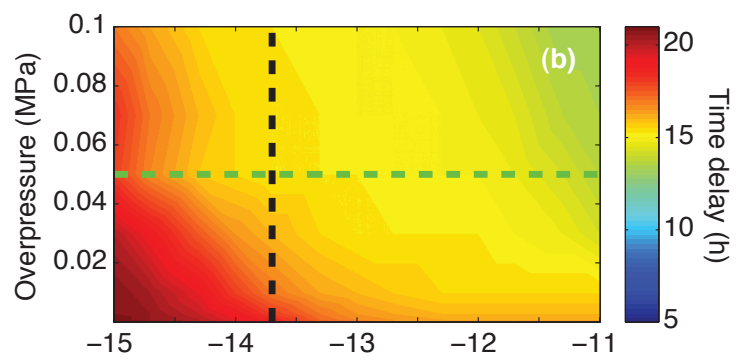

Log (permeability) $\left(\mathrm{m}^{2}\right)$

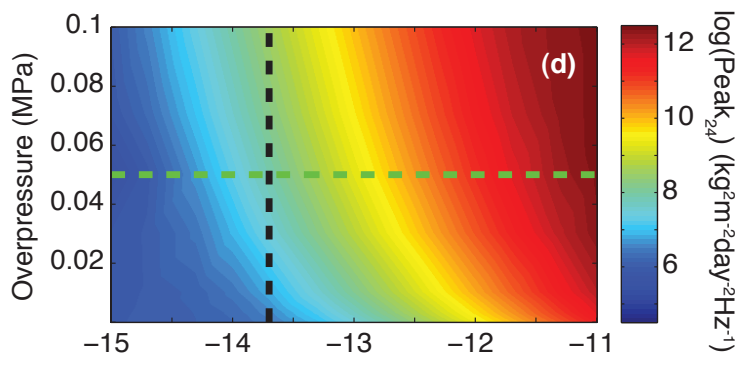

Log (permeability) $\left(\mathrm{m}^{2}\right)$

Figure 11. Dual parameter study: time delays and peak amplitudes of the $\mathrm{CO}_{2}$ gas flux as a function of both gas reservoir overpressure and rock permeability. (a) Time delay of the $12 \mathrm{~h}$ component with respect to the barometric pressure. (b) Time delay of the $24 \mathrm{~h}$ component with respect to the air temperature. (c) Peak amplitude of the $12 \mathrm{~h}$ component. (d) Peak amplitude of the $24 \mathrm{~h}$ component. Black and green line represents in all figures the value used previously for the analysis of the degassing as a function of only the rock permeability or gas reservoir overpressure, respectively. 

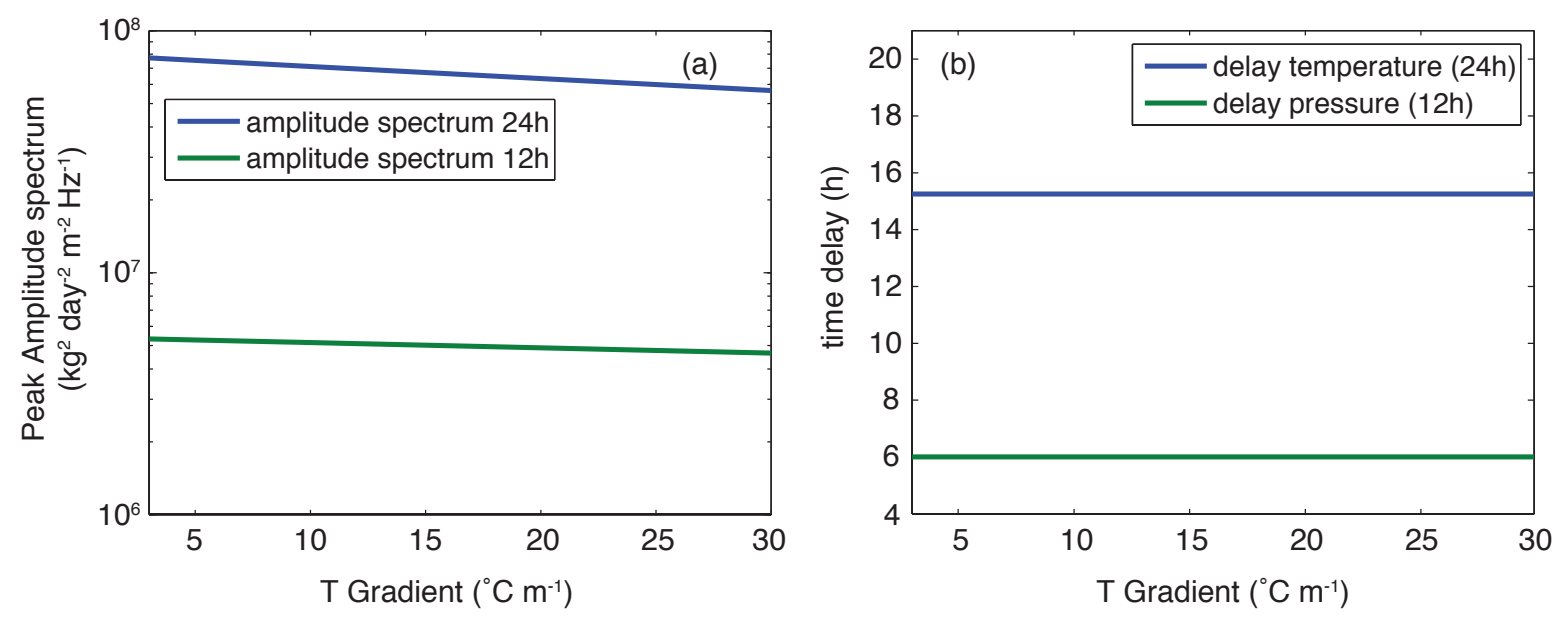

Figure 12. (a) Peak amplitude in the spectrum of the $\mathrm{CO}_{2}$ flux as a function of the temperature gradient for the $12 \mathrm{~h}$ (green line) and $24 \mathrm{~h}$ (blue line) component, respectively. (b) Time delay as a function of the temperature, with respect the pressure (12h component, green line) and temperature (24h component, blue line), respectively. For this set of simulations domain permeability and gas reservoir overpressure were fixed as in the base case $\left(2 \cdot 10^{-14} \mathrm{~m}^{2}\right.$, and $0.05 \mathrm{MPa}$, respectively). 